Article

\title{
Competence for Natural Transformation Is Common among Clinical Strains of Resistant Acinetobacter spp.
}

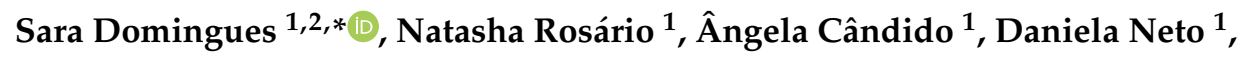 \\ Kaare M. Nielsen ${ }^{3}(D)$ and Gabriela J. Da Silva ${ }^{1,2}$ \\ 1 Faculty of Pharmacy, University of Coimbra, 3000-458 Coimbra, Portugal; narosario@live.com.pt (N.R.); \\ angelandrade_93@hotmail.com (Â.C.); danielaneto471@hotmail.com (D.N.); gjsilva@ci.uc.pt (G.J.D.S.) \\ 2 Centre for Neuroscience and Cell Biology, University of Coimbra, 3004-517 Coimbra, Portugal \\ 3 Department of Life Sciences and Health, Oslo Metropolitan University, N-0130 Oslo, Norway; \\ kamni@oslomet.no \\ * Correspondence: saradomingues@ff.uc.pt; Tel.: +351-239-488-446
}

Received: 7 December 2018; Accepted: 22 January 2019; Published: 24 January 2019

\begin{abstract}
Horizontal gene transfer events provide the basis for extensive dissemination of antimicrobial resistance traits between bacterial populations. Conjugation is considered to be the most frequent mechanism behind new resistance acquisitions in clinical pathogens but does not fully explain the resistance patterns seen in some bacterial genera. Gene transfer by natural transformation has been described for numerous clinical isolates, including some Acinetobacter species. The main aim of this study was to determine to what extent clinical, resistant Acinetobacter spp. isolates, express competence for natural transformation. Twenty-two clinical Acinetobacter spp. isolates collected over a 16-year time period, from five different geographical separated and/or distinct Portuguese Hospitals were tested for natural transformability. Fourteen isolates, including 11 A. baumannii, 2 A. nosocomialis and 1 Acinetobacter sp., were identified as competent on semisolid media facilitating surface-motility. Competent Acinetobacter isolates were found in all the hospitals tested. Furthermore, osmolarity was shown to influence the uptake of exogenous DNA by competent $A$. baumannii A118. Our study demonstrates that natural competence is common among clinical isolates of Acinetobacter spp., and hence likely an important trait for resistance acquisition.
\end{abstract}

Keywords: Acinetobacter baumannii; Acinetobacter nosocomialis; clinical isolates; horizontal gene transfer; natural transformation; competence; osmolarity

\section{Introduction}

Antimicrobial resistance is considered a major threat to public health [1]. Most pathogenic microorganisms have acquired some resistance to many of the commonly used antibiotics. Among these are the so-called ESKAPE pathogens, which include Enterococcus faecium, Staphylococcus aureus, Klebsiella pneumoniae, Acinetobacter baumannii, Pseudomonas aeruginosa and Enterobacter spp. [2]. These are highly important nosocomial pathogens that are now becoming resistant to the majority of the available antibiotics. A. baumannii strains were initially susceptible to most of the antimicrobials in the early 70s, when resistance started to develop [3]. A. baumannii has emerged as an important nosocomial pathogen, and nowadays some strains are only susceptible to carbapenems and colistin [4]. Due to the lack of therapeutic options, this species has been classified as critical in the priority pathogens list released by the World Health Organization in 2017 [5].

Horizontal gene transfer (HGT) mechanisms play a crucial role in the dissemination of antimicrobial resistance worldwide [6]. Conjugation is often reported as the causal mechanism 
of gene transfer associated with the wide dissemination of many resistance genes [1]. However, resistance in A. baumannii cannot be fully explained by the acquisition of conjugative plasmids [4]. It is well known that environmental Acinetobacter species can express competence and undergo natural transformation $[7,8]$. Competence development contributes to the acquisition of antimicrobial resistance genes and mobile genetic elements from unrelated species in Acinetobacter [9]. However, this HGT mechanism has been poorly explored in clinical strains, which are often multidrug resistant. In 2010, an A. baumannii clinical isolate with the ability to undergo natural transformation was identified for the first time in Buenos Aires [10]. Later, an Acinetobacter nosocomialis strain, another important hospital pathogen isolated in the United States, was also reported to be naturally transformable [11,12]. Three other studies also described the presence of naturally competent $A$. baumannii isolates of human clinical [13], animal clinical [14] and animal non-clinical [15] origin. Transformability of A. baumannii has been shown to be influenced by different conditions such as the presence of $\mathrm{Ca}^{2+}$-ions and albumin $[14,16]$, the $\mathrm{pH}[14,16]$, the presence of sub-inhibitory concentrations of mitomycin C, nalidixic acid and meropenem [17], or the agarose concentration [14]; however, the influence of these parameters seems to be strain-dependent $[14,16]$. Despite the fact that natural transformation is now well established as a common trait in Acinetobacter species, only one study has screened the ability to undergo natural competence in a set of human clinical isolates [13]. The primary objective of this work was to determine to what extent human clinical isolates of Acinetobacter species associated with human infections are able to express competence during growth in vitro. The effects of osmolarity variations in competence and in cells growth were also tested.

\section{Materials and Methods}

\subsection{Bacterial Isolates and Growth Conditions}

From our collection of clinical Acinetobacter spp., we selected and tested 22 kanamycin susceptible clinical isolates collected between 1992 and 2008. The isolates originated from five different geographical and/or distinct Portuguese hospitals (Table 1) and had different resistant profiles. The naturally competent $A$. baumannii A118 clinical strain was included as a positive control for transformability [10].

Bacteria were grown in Luria-Bertani (LB) (Fluka, Saint Louis, MO, USA) agar (Liofilchem, Roseto d. Abruzzi, Italy) medium and incubated at $37^{\circ} \mathrm{C}$. The ability of the various isolates to undergo natural transformation was examined during growth on plates containing $0.5 \%$ agar (Liofilchem), $5 \mathrm{~g} / \mathrm{L}$ tryptone (Difco, Sparks, MD, USA) and $2.5 \mathrm{~g} / \mathrm{L}$ sodium chloride (Scharlau, Sentmenat, Spain) [13], here called Motility Medium (MM).

Transformant cells were selected on LB plates supplemented with $30 \mu \mathrm{g} / \mathrm{mL}$ of kanamycin (Sigma, Saint Louis, MO, USA).

The competent isolates detected in this study were identified to the species level by sequencing of the $r p o B$ gene [18] (sequencing provider STAB VIDA, Portugal).

\subsection{Growth Curve Under Different Sodium Chloride Concentrations}

An overnight culture of $A$. baumannii A118 was prepared by inoculation of a single colony into $5 \mathrm{~mL}$ of LB broth, followed by incubation at $37^{\circ} \mathrm{C}$ with good aeration (120 rpm). A 1:100 dilution into $50 \mathrm{~mL}$ of fresh LB broth containing tryptone $(10 \mathrm{~g} / \mathrm{L})$, yeast extract $(5 \mathrm{~g} / \mathrm{L})$ (Difco) and sodium chloride $(0.5,2.5,5,7.5$ or $10 \mathrm{~g} / \mathrm{L})$ was done, followed by incubation at $37^{\circ} \mathrm{C}$ and agitation at $120 \mathrm{rpm}$ for $320 \mathrm{~min}$. Samples were collected at 30 and $60 \mathrm{~min}$ and then each $20 \mathrm{~min}$, and the optical density at $600 \mathrm{~nm}\left(\mathrm{OD}_{600 \mathrm{~nm}}\right)$ was measured in a spectrophotometer (Genesys 10UV, Thermo Scientific, Madison, WI, USA). The growth curves were constructed plotting the $\mathrm{OD}_{600 \mathrm{~nm}}$ values versus the incubation time. 


\subsection{Natural Transformation}

Natural competence of the 22 clinical Acinetobacter spp. isolates was tested with the transformation protocol described by Wilharm et al. [13]. Briefly, a single colony was suspended in $20 \mu \mathrm{L}$ of sterile phosphate-buffered saline (PBS) and mixed with $20 \mu \mathrm{L}$ of DNA (4 $\mu \mathrm{g}$ in water); the MM was stabbed seven times depositing $2 \mu \mathrm{L}$ of the transformation mixture each time; the plate was sealed with Parafilm and incubated at $37{ }^{\circ} \mathrm{C}$ for $24 \mathrm{~h}$; bacteria were recovered from the medium surface and suspended in $1 \mathrm{~mL}$ of PBS, followed by selection on LB agar with kanamycin. Initial transformation of $A$. baumannii 121 was performed with purified chromosomal DNA from the A. baumannii mutant 179 , which has a kanamycin resistance gene inserted into the sulphite reductase gene [13], kindly provided by G. Wilharm. DNA extracted from a transformant named 121-1, containing the kanamycin marker, was then used as transforming DNA for all subsequent transformation tests. Detection of competent isolates relied on the incorporation of the marker into the chromosome of the recipient cell by homologous recombination. Negative controls were always included in each transformation experiment, using water instead of donor DNA. Three independent transformation experiments were performed for all isolates that initially failed to produce transformants.

The same transformation protocol was used in transformation assays with the competent A. baumannii A118 under different concentrations of sodium chloride $(0.5,2.5,5,7.5$ or $10 \mathrm{~g} / \mathrm{L})$.

The transformation frequency was calculated as the ratio between the number of transformants and the total number of cells. A minimum of two independent transformation experiments, each repeated in triplicate, were done.

\subsection{Transformants Confirmation}

The Colony Forming Units (CFUs) that grew on LB plates with kanamycin were considered possible transformants. Selected cells were re-streaked and tested by PCR targeting the sulphite reductase gene [13], using the MasterMix Dynazyme II (Finnzymes, Finland). Bacterial cells that acquired the transforming DNA produce a PCR amplicon of approx. $2400 \mathrm{bp}$, while in wildtype cells this locus gives an amplicon size of $1200 \mathrm{bp}$ due to the absence of the insert (G. Wilharm, personal communication).

\section{Results and Discussion}

Fourteen clinical Acinetobacter spp. isolates were detected as naturally transformable (Table 1). The majority were identified as A. baumannii $(n=11)$, the most relevant nosocomial species, while two were $A$. nosocomialis and one isolate could not be identified to the species level. The ability to undergo natural transformation was detected in isolates from all hospitals, which suggests that resistant isolates with the ability to develop competence are widespread in the clinical environment. Moreover, such strains with the ability to express competence have been circulating in the hospital environment for a long time. This HGT trait can explain the increased antimicrobial resistance seen in this species in the last decades. The acquisition events of antimicrobial resistance by natural transformation may have been further promoted by the selection exerted by the increased use of antibiotics in the hospital environment. A recent study observed that strains circulating in the hospital environment show evidence of HGT and other genetic events, making almost every A. baumannii strain unique, despite their genetic relatedness determined by conventional typing methods such as MLST [19]. 
Table 1. Natural competence in clinical Acinetobacter spp. isolates.

\begin{tabular}{|c|c|c|c|c|}
\hline Isolate & Species & Year of Isolation & Hospital/Region & Natural Competence $^{a}$ \\
\hline 013 & A. nosocomialis & 1992 & HUC/Coimbra & + \\
\hline 015 & A. baumannii & 1994 & HUC/Coimbra & + \\
\hline 113 & A. baumannii & 1998 & HUC/Coimbra & + \\
\hline 118 & A. bereziniae & 1998 & HUC/Coimbra & - \\
\hline 121 & A. baumannii & 1998 & HUC/Coimbra & + \\
\hline 129 & A. baumannii & 1998 & HUC/Coimbra & + \\
\hline 132 & A. baumannii & 1998 & HUC/Coimbra & + \\
\hline 138022 F1Ev & n.d. & 2008 & HES/Évora & - \\
\hline $144417 \mathrm{M} 1 \mathrm{Ev}$ & A. baumannii & 2008 & HES/Évora & + \\
\hline 213 & n.d. & 2004 & HSAC/Lisbon & - \\
\hline 241 & A. baumannii & 2005 & HSAC/Lisbon & + \\
\hline 245 & A. baumannii & 2005 & HSAC/Lisbon & - \\
\hline 274 & A. baumannii & 2006 & HSAC/Lisbon & - \\
\hline 292 & A. baumannii & 2006 & HSAC/Lisbon & + \\
\hline 319 & A. baumannii & 2007 & HSAC/Lisbon & + \\
\hline $326744 \mathrm{C} 1 \mathrm{Ev}$ & A. nosocomialis & 2008 & HES/Évora & + \\
\hline 3605 & n.d. & 1994 & Porto & - \\
\hline 3625 & A. baumannii & 1995 & Porto & + \\
\hline 532331 A1Ev & A. baumannii & 2008 & HES/Évora & + \\
\hline 545663 F2Ev & A. baumannii & 2008 & HES/Évora & - \\
\hline 065 & Acinetobacter sp. & 1999 & HSM/Lisbon & + \\
\hline $65 \mathrm{FFC}$ & A. baumannii & 1998 & HUC/Coimbra & - \\
\hline
\end{tabular}

Although the donor DNA used in this study was homologous to A. baumannii (gene A1S_2846 in A. baumannii ATCC 17978) [13], two A. nosocomialis isolates were found to be transformable. Both species belong to the Acinetobacter calcoaceticus- $A$. baumannii complex that share genetic homology and are frequently found in the clinical environment [20]. Increasing genetic divergence reduces transformation frequency in Acinetobacter [21]. We can therefore not exclude the possibility that some of the other Acinetobacter spp. isolates tested here might be transformable but are so genetically divergent from the $A$. baumannii donor DNA that they turned out negative.

Several factors influence the natural transformation of $A$. baumannii cells. Two studies observed differences in the natural transformability of $A$. baumannii isolates depending on the type of transforming DNA (chromosomal versus plasmid DNA) [13,14]. However, a recent study showed that the transformability of A. baumannii A118 was not affected by the donor DNA type, temperature and osmolarity; on the other hand, transformation was influenced by the $\mathrm{pH}$ of the medium, with a higher transformation frequency obtained at 7.5, and both the presence of $\mathrm{Ca}^{2+}$-ions and albumin were shown to induce competence [16]. The authors concluded that the transformation frequency is impacted by the medium's composition. The influence of different parameters seems however to be strain dependent, as in a recent study with $A$. baumannii AB5075, albumin was shown to decrease transformability, and the optimal $\mathrm{pH}$ for transformation was between 5.3 and 6.1; this study also showed that transformation frequencies increase with agarose concentration [14]. In our study, we used a different medium, MM, as well as different conditions for DNA exposure. In our experimental conditions, we observed that osmolarity influenced the transformability of A. baumannii A118, with transformation rates occurring at similar levels $\left(10^{-5}\right)$ in medium with $0.5,2.5$ and $5 \mathrm{~g} / \mathrm{L}$ of sodium chloride, but two orders of magnitude lower $\left(10^{-7}\right)$ under higher amounts of salt (Table 2$)$. The transformability was not related to differences in the growth rate of the cells, as growth was similar in all tested concentrations (Figure 1). In addition, we observed that transformation frequencies in semisolid medium were higher $\left(10^{-5}\right)$ than those obtained in liquid medium in other studies $\left(10^{-7}\right)$ [16]. Therefore, in addition to the specific composition of the growth medium, the overall growth conditions and pattern of DNA exposure also influence the transformability of $A$. baumannii A118. This finding suggests that transformability will change with environments and the various opportunities for growth of A. baumannii cells in vivo. 
Table 2. Effects of sodium chloride on the transformation frequency of Acinetobacter baumannii A118 in semi-solid medium.

\begin{tabular}{|c|c|c|c|}
\hline $\mathrm{NaCl}$ Concentration & $\begin{array}{l}\text { Mean Number of } \\
\text { Transformants (CFU) } \pm \text { SD }\end{array}$ & $\begin{array}{l}\text { Mean Number of Total } \\
\text { Cells (CFU) } \pm \text { SD }\end{array}$ & $\begin{array}{l}\text { Transformation } \\
\text { Frequency }\end{array}$ \\
\hline $0.5 \mathrm{~g} / \mathrm{L}$ & $(4.73 \pm 3.11) \times 10^{4}$ & $(1.14 \pm 0.65) \times 10^{8}$ & $4.1 \times 10^{-5}$ \\
\hline $2.5 \mathrm{~g} / \mathrm{L}$ & $(3.65 \pm 4.30) \times 10^{4}$ & $(6.38 \pm 3.30) \times 10^{8}$ & $5.7 \times 10^{-5}$ \\
\hline $5 \mathrm{~g} / \mathrm{L}$ & $(9.11 \pm 6.68) \times 10^{3}$ & $(5.27 \pm 3.04) \times 10^{8}$ & $1.7 \times 10^{-5}$ \\
\hline $7.5 \mathrm{~g} / \mathrm{L}$ & $(5.28 \pm 56.1) \times 10^{2}$ & $(8.14 \pm 8.61) \times 10^{8}$ & $6.5 \times 10^{-7}$ \\
\hline $10 \mathrm{~g} / \mathrm{L}$ & $(1.35 \pm 1.58) \times 10^{2}$ & $(7.88 \pm 2.32) \times 10^{8}$ & $1.7 \times 10^{-7}$ \\
\hline
\end{tabular}

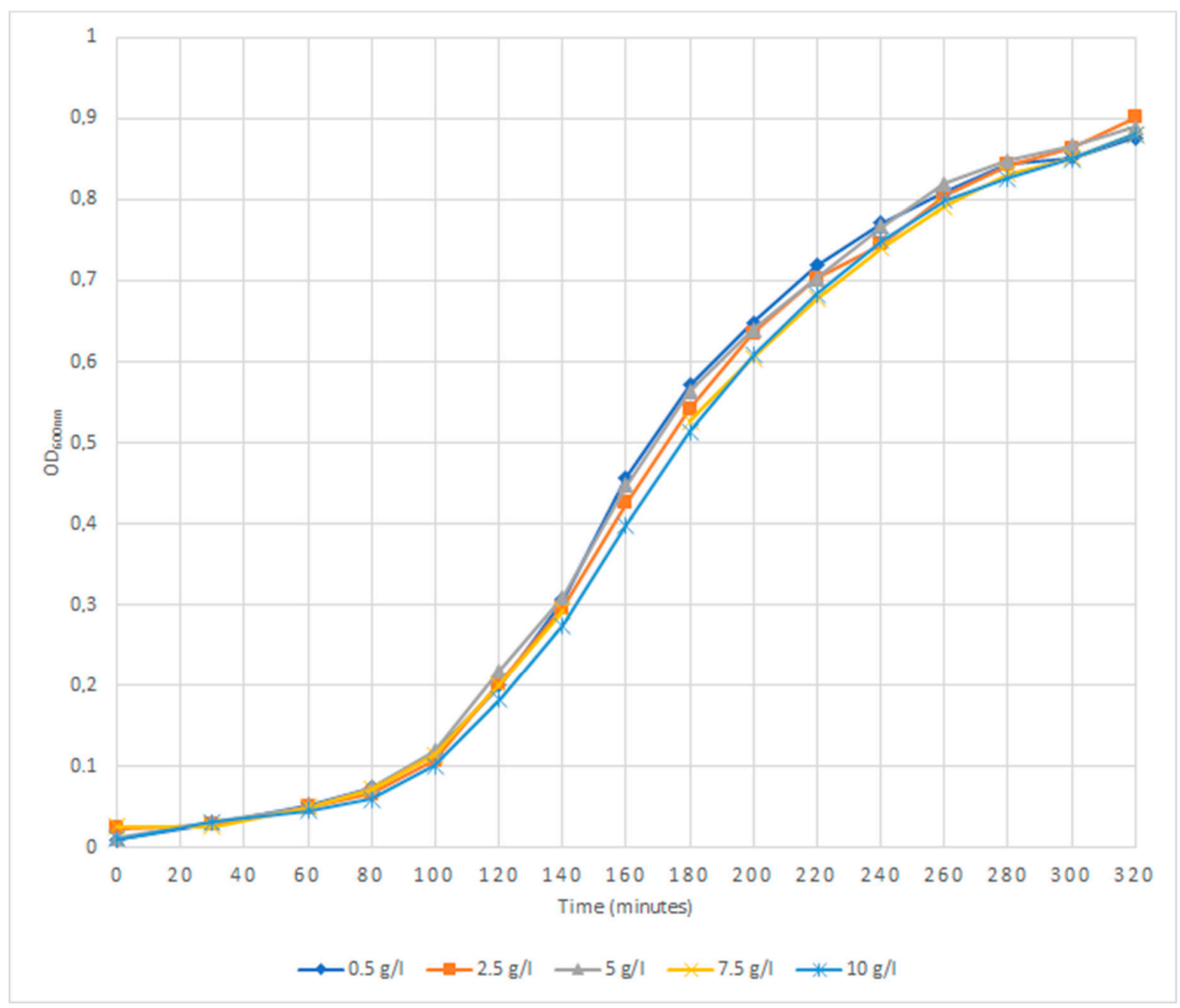

Figure 1. Effect of sodium chloride on the growth of Acinetobacter baumannii A118.

The previous reports and the present findings confirm that resistant clinical bacteria species, A. baumannii and A. nosocomialis are able to undergo natural transformation, supporting the hypothesis that natural transformation might be a mechanism for resistance acquisition in the clinical setting. Components of some biological fluids $\left(\mathrm{Ca}^{2+}\right.$-ions and albumin) can induce transformation in A. baumannii, suggesting that Acinetobacter can develop competence in vivo [16]. A recent study has shown higher transformability of two A. baumannii clinical strains in biologic fluids containing a significant amount of albumin, such as pleural fluid, ascites fluid and whole blood [22]. Here, we also show that despite the frequency differences seen under the various concentrations of sodium chloride, transformation of A. baumannii A118 occurs at detectable levels in all tested salinity conditions, including those found in vivo (usually $\mathrm{Na}^{+}$is present at a $3 \mathrm{~g} / \mathrm{L}$ in human serum) (Table 2).

Some of the A. baumannii isolates did not produce transformants in all replicates (data not shown). This might indicate that competence is tightly regulated in the studied bacterial population and that 
small variations in growth conditions led to minor differences in growth trajectories and conditions that altered their level of competence. Transformation can also be strain dependent; more strains need to be tested in order to widen our understanding of the true distribution of competence among Acinetobacter spp. More detailed system studies should be performed to fully dissect competence triggering conditions. Knowledge of the environmental conditions and bacterial population features that induce and maintain competence in clinical isolates is crucial to fully understand bacterial adaptation, particularly for antimicrobial agents, one of the biggest problems of this century.

Author Contributions: S.D., K.M.N. and G.J.D.S. conceived and designed the experiments; S.D., N.R., Â.C. and D.N. performed the experiments; S.D. and G.J.D.S. analysed the data; S.D., K.M.N. and G.J.D.S. draft the manuscript. All authors read and approved the final manuscript.

Funding: This work was supported by the Faculty of Pharmacy of the University of Coimbra; and FEDER funds through the "Programa Operacional Factores de Competitividade-COMPETE 2020" and by National Funds from "FCT—Fundação para a Ciência e a Tecnologia no âmbito do projecto Estratégico: UID/NEU/04539/2013".

Acknowledgments: We thank G. Wilharm for the gift of A. baumannii 179 DNA and his helpful discussion on the setup of the growth conditions. KMN acknowledges the activities of the EU COST action ESSEM ES1403 NEREUS.

Conflicts of Interest: The authors declare no conflict of interest.

\section{References}

1. Smalla, K.; Cook, K.; Djordjevic, S.P.; Klumper, U.; Gillings, M. Environmental dimensions of antibiotic resistance: Assessment of basic science gaps. FEMS Microbiol. Ecol. 2018, 94, fiy195. [CrossRef] [PubMed]

2. Rice, L.B. Federal funding for the study of antimicrobial resistance in nosocomial pathogens: No ESKAPE. J. Infect. Dis. 2008, 197, 1079-1081. [CrossRef] [PubMed]

3. Bergogne-Berezin, E.; Joly-Guillou, M.L. An underestimated nosocomial pathogen Acinetobacter calcoaceticus. J. Antimicrob. Chemother. 1985, 16, 535-538. [CrossRef] [PubMed]

4. Da Silva, G.J.; Domingues, S. Insights on the horizontal gene transfer of carbapenemase determinants in the opportunistic pathogen Acinetobacter baumannii. Microorganisms 2016, 4, 23. [CrossRef] [PubMed]

5. Tacconelli, E.; Magrini, N. Global Priority List of Antibiotic-Resistant Bacteria to Guide Research, Discovery, and Development of New Antibiotics; World Health Organization: Geneva, Switzerland, 2017.

6. von Wintersdorff, C.J.; Penders, J.; van Niekerk, J.M.; Mills, N.D.; Majumder, S.; van Alphen, L.B.; Savelkoul, P.H.; Wolffs, P.F. Dissemination of antimicrobial resistance in microbial ecosystems through horizontal gene transfer. Front. Microbiol. 2016, 7, 173. [CrossRef] [PubMed]

7. Domingues, S.; Nielsen, K.M. Horizontal gene transfer: Uptake of extracellular DNA by bacteria. In Reference Module in Biomedical Sciences; Elsevier: Amsterdam, The Netherlands, 2016.

8. Barbe, V.; Vallenet, D.; Fonknechten, N.; Kreimeyer, A.; Oztas, S.; Labarre, L.; Cruveiller, S.; Robert, C.; Duprat, S.; Wincker, P.; et al. Unique features revealed by the genome sequence of Acinetobacter sp. ADP1, a versatile and naturally transformation competent bacterium. Nucleic Acids Res. 2004, 32, 5766-5779. [CrossRef] [PubMed]

9. Domingues, S.; Harms, K.; Fricke, W.F.; Johnsen, P.J.; da Silva, G.J.; Nielsen, K.M. Natural transformation facilitates transfer of transposons, integrons and gene cassettes between bacterial species. PLoS Pathog. 2012, 8, e1002837. [CrossRef] [PubMed]

10. Ramirez, M.S.; Don, M.; Merkier, A.K.; Bistue, A.J.; Zorreguieta, A.; Centron, D.; Tolmasky, M.E. Naturally competent Acinetobacter baumannii clinical isolate as a convenient model for genetic studies. J. Clin. Microbiol. 2010, 48, 1488-1490. [CrossRef] [PubMed]

11. Carruthers, M.D.; Harding, C.M.; Baker, B.D.; Bonomo, R.A.; Hujer, K.M.; Rather, P.N.; Munson, R.S., Jr. Draft genome sequence of the clinical isolate Acinetobacter nosocomialis strain M2. Genome Announc. 2013, 1, e00906-13. [CrossRef] [PubMed]

12. Harding, C.M.; Tracy, E.N.; Carruthers, M.D.; Rather, P.N.; Actis, L.A.; Munson, R.S., Jr. Acinetobacter baumannii strain M2 produces type IV pili which play a role in natural transformation and twitching motility but not surface-associated motility. MBio 2013, 4, e00360-13. [CrossRef] [PubMed]

13. Wilharm, G.; Piesker, J.; Laue, M.; Skiebe, E. DNA uptake by the nosocomial pathogen Acinetobacter baumannii occurs during movement along wet surfaces. J. Bacteriol. 2013, 195, 4146-4153. [CrossRef] [PubMed] 
14. Godeux, A.S.; Lupo, A.; Haenni, M.; Guette-Marquet, S.; Wilharm, G.; Laaberki, M.H.; Charpentier, X. Fluorescence-based detection of natural transformation in drug resistant Acinetobacter baumannii. J. Bacteriol. 2018, 200, e00181-18. [CrossRef] [PubMed]

15. Wilharm, G.; Skiebe, E.; Higgins, P.G.; Poppel, M.T.; Blaschke, U.; Leser, S.; Heider, C.; Heindorf, M.; Brauner, P.; Jackel, U.; et al. Relatedness of wildlife and livestock avian isolates of the nosocomial pathogen Acinetobacter baumannii to lineages spread in hospitals worldwide. Environ. Microbiol. 2017, 19, 4349-4364. [CrossRef] [PubMed]

16. Traglia, G.M.; Quinn, B.; Schramm, S.T.; Soler Bistue, A.; Ramirez, M.S. Serum albumin and Ca ${ }^{2+}$ are natural competence inducers in the human pathogen Acinetobacter baumannii. Antimicrob. Agents Chemother. 2016, 60, 4920-4929. [CrossRef] [PubMed]

17. Quinn, B.; Martinez, J.; Liu, C.; Nguyen, M.; Ramirez, M.S. The effect of sub-inhibitory concentrations of antibiotics on natural transformation in Acinetobacter baumannii. Int. J. Antimicrob. Agents 2018, 51, 809-810. [CrossRef] [PubMed]

18. La Scola, B.; Gundi, V.A.; Khamis, A.; Raoult, D. Sequencing of the rpoB gene and flanking spacers for molecular identification of Acinetobacter species. J. Clin. Microbiol. 2006, 44, 827-832. [CrossRef] [PubMed]

19. Wright, M.S.; Haft, D.H.; Harkins, D.M.; Perez, F.; Hujer, K.M.; Bajaksouzian, S.; Benard, M.F.; Jacobs, M.R.; Bonomo, R.A.; Adams, M.D. New insights into dissemination and variation of the health care-associated pathogen Acinetobacter baumannii from genomic analysis. MBio 2014, 5, e00963-13. [CrossRef] [PubMed]

20. Nemec, A.; Krizova, L.; Maixnerova, M.; van der Reijden, T.J.; Deschaght, P.; Passet, V.; Vaneechoutte, M.; Brisse, S.; Dijkshoorn, L. Genotypic and phenotypic characterization of the Acinetobacter calcoaceticus-Acinetobacter baumannii complex with the proposal of Acinetobacter pittii sp. nov. (formerly Acinetobacter genomic species 3) and Acinetobacter nosocomialis sp. nov. (formerly Acinetobacter genomic species 13TU). Res. Microbiol. 2011, 162, 393-404. [PubMed]

21. Ray, J.L.; Harms, K.; Wikmark, O.G.; Starikova, I.; Johnsen, P.J.; Nielsen, K.M. Sexual isolation in Acinetobacter baylyi is locus-specific and varies 10,000-fold over the genome. Genetics 2009, 182, 1165-1181. [CrossRef] [PubMed]

22. Martinez, J.; Liu, C.; Rodman, N.; Fernandez, J.S.; Barberis, C.; Sieira, R.; Perez, F.; Bonomo, R.A.; Ramirez, M.S. Human fluids alter DNA-acquisition in Acinetobacter baumannii. Diagn Microbiol. Infect. Dis. 2018. [CrossRef] [PubMed] 